\title{
BMJ Open Qualitative analysis of a virtual research meeting summarises expert-based strategies to promote hydration in residential care during COVID-19 and beyond
}

\author{
Heather Keller (D) ${ }^{1,2}$ Cindy Wei, ${ }^{2}$ Susan Slaughter, ${ }^{3}$ Minn N Yoon, ${ }^{4}$ \\ Christina Lengyel, ${ }^{5}$ Ashwin Namasivayam-Macdonald, ${ }^{6}$ Laurel Martin, ${ }^{5}$ \\ George Heckman, ${ }^{1,7}$ Phyllis Gaspar, ${ }^{8}$ Janet Mentes, ${ }^{9}$ Safura Syed ${ }^{2}$
}

To cite: Keller $\mathrm{H}$, Wei $\mathrm{C}$, Slaughter S, et al. Qualitative analysis of a virtual research meeting summarises expertbased strategies to promote hydration in residential care during COVID-19 and beyond. BMJ Open 2022;12:e055457. doi:10.1136/ bmjopen-2021-055457

- Prepublication history for this paper is available online. To view these files, please visit the journal online (http://dx.doi. org/10.1136/bmjopen-2021055457).

Received 15 July 2021 Accepted 19 January 2022

Check for updates

(C) Author(s) (or their employer(s)) 2022. Re-use permitted under CC BY-NC. No commercial re-use. See rights and permissions. Published by BMJ.

For numbered affiliations see end of article.

Correspondence to Dr Heather Keller; hkeller@uwaterloo.ca

\section{ABSTRACT}

Objectives Poor fluid intake is a complex and longstanding issue in residential care, further exacerbated by COVID-19 infection control procedures. There is no consensus on how best to prevent dehydration in residents who vary in their primary reasons for insufficient fluid intake for a variety of reasons. The objectives of this research were to determine expert and provider perspectives on: (1) how COVID-19 procedures impacted hydration in residential care and potential solutions to mitigate these challenges and (2) strategies that could target five types of residents based on an oral hydration typology focused on root causes of low fluid intake.

Design Qualitative study based on virtual group discussion. The discussion was audiorecorded with supplementary field notes. Qualitative content analysis was completed.

Setting Residential care.

Participants 27 invited researcher and provider experts. Results Challenges that have potentially impacted hydration of residents because of COVID-19 procedures were categorised as resident (eg, apathy), staff (eg, new staff) and home-related (eg, physical distancing in dining rooms). Potential solutions were offered, such as fun opportunities (eg, popsicle) for distanced interactions; training new staff on how to approach specific residents and encourage drinking; and automatically providing water at meals. Several strategies were mapped to the typology of five types of residents with low intake (eg, sipper) and categorised as: supplies (eg, vessels with graduated markings), timing (eg, identify best time of day for drinking), facility context (eg, identify preferred beverages), socialisation (eg, promote drinking as a social activity) and education (eg, educate cognitively well on water consumption goals).

Conclusions COVID-19 has necessitated new procedures and routines in residential care, some of which can be optimised to promote hydration. A variety of strategies to meet the hydration needs of different subgroups of residents can be compiled into multicomponent interventions for future research.

\section{Strengths and limitations of this study}

- An oral hydration typology was used to guide discussion on interventions for discrete groups of residents based on their primary reason for low intake.

- The experience of the 27 participants, 10 of whom were part of the research team, was diverse.

- Virtual technology required due to the COVID-19 pandemic allowed for wide geographical participation, but limited the time for engagement of the expert group.

\section{INTRODUCTION}

Older adults living in residential care (eg, nursing homes, long-term care, assisted living or retirement homes) are at an increased risk for inadequate food and fluid intake. ${ }^{12}$ Recent research suggests that the average fluid intake is $\sim 1100 \mathrm{~mL}$ per day, ${ }^{3}$ which is well below recommendations for older adults. ${ }^{45}$ Low fluid intake can result in dehydration with subsequent delirium, falls and avoidable hospitalisations. ${ }^{2}{ }^{6}$ Without an adequate test to demonstrate impending dehydration, ${ }^{7}$ the best strategy is prevention by ensuring sufficient fluid intake.

Resident, staff and home factors work synergistically to impact fluid intake. ${ }^{8}$ Residents have decreased thirst drive, lower body fluid and an inability to concentrate urine. ${ }^{2}$ Although medications and disease states also impact hydration, ${ }^{9}$ low fluid intake is the primary mechanism driving dehydration in residential care. ${ }^{2}$ Age, sex, cognitive impairment, eating challenges, dysphagia, inability to communicate verbally, depression and loneliness, and functional dependence for eating and drinking are associated with low fluid intake. ${ }^{3610-13}$ Yet, these associations are 
complex. For example, residents who need some, but not total eating support, have lower fluid intake compared with those who require full support ${ }^{1}$; however, more staff in the dining room does not ensure adequate fluid intake. ${ }^{3}$ Beyond numbers, staff may have inadequate mechanisms for monitoring resident fluid intake and communicating this among the team, and/or have competing priorities. ${ }^{13-15}$ Availability of preferences,${ }^{914}$ including a variety of thickened fluid options, as well as hydration stations, and/or delivery of between-meal fluids ${ }^{11}$ are often decisions made at the home level that impact resident hydration.

Proactive solutions are needed to address the complexity of hydration in residential care. A hydration typology has been created which categorises each resident based on the primary characteristics that limit their fluid intake. ${ }^{16}$ This typology was created based on a longitudinal observation of nursing home residents in two homes, including determination of hydration based on their urine specific gravity, bioimpedance and meal intake records, and informal interviews with staff. This typology provides guidance for strategies to promote fluid intake in four overall groups and six subgroups. The four main groups identify the root cause of low intake and although discrete, can often co-occur in residents: those who can drink, those who can't drink, those who won't drink, and those at endof-life. ${ }^{16}$ Those who can drink are subdivided into those who are physically independent or have cognitive impairment, but do not require eating assistance. Those who can't drink are subdivided into those who require physical help with drinking or have dysphagia, necessitating thickened fluids. Those who won't drink were subdivided into 'sippers' who only consume small amounts of fluids or those who avoid fluid intake for fear of urinary incontinence. ${ }^{16}$ The end-of-life category was not further subdivided; strategies observed in the homes to overcome these reasons for low intake were also provided. ${ }^{16}$

The current global pandemic has dramatically highlighted the vulnerability of residents, not only for the spread of SARS-COV-2- or COVID-19-related deaths but also for the collateral consequences of procedures implemented to reduce susceptibility and spread of the virus. ${ }^{1718}$ There is currently limited data on the impacts of these procedures on the nutritional health and hydration of residents. Based on media and anecdotal reports, ${ }^{19}$ nutritional side effects are potentially considerable.

The objectives of this research were to determine expert and provider perspectives on: (1) how COVID-19 procedures had impacted hydration in residential care and potential solutions to mitigate these challenges and (2) strategies that could target key groups in the hydration typology ${ }^{16}$ for consideration in a future multicomponent intervention.

\section{METHODS}

This meeting was originally planned for April 2020 as an in-person all-day think tank to identify feasible strategies to consider for a multicomponent hydration intervention for residential care based on the hydration typology. ${ }^{16}$ It was rescheduled for June 2020, after the first wave of the global COVID-19 pandemic, as a virtual 3-hour meeting. The original think tank participants (experts in hydration, representatives of residential care provider roles (eg, food service manager)) were invited, and the list expanded to include more residential care providers. A total of 36 were invited to the think tank, including the research team. These invitees were from the professional networks of the research team and thus, some participants were known to the authors but were not considered close colleagues. The researcher leading the meeting (HK; senior researcher with expertise in geriatric nutrition) has extensive experience in qualitative methods and leading large group discussions. The research team included experts in speech-language pathology, nursing, hydration, oral health, dietetics and geriatric medicine; all had experience conducting research in residential care. Two research assistants were also part of the research team. Confirmed participants provided a short biography and photo, as well as a signed consent form before the virtual meeting and sent this to the research lead via email. An overview of the oral hydration typology and background on potential hydration strategies was sent to participants before the meeting to stimulate thoughts on strategies before the meeting.

As the COVID-19 pandemic had precipitated changes in practice in residential care, the focus of the think tank was expanded to consider the effects of the pandemic on strategies to support hydration in residential care. The meeting was designed to be consistent with best practices for virtual focus groups. ${ }^{20}$ The 3 -hour meeting was divided into four segments: (1) introductions followed by a short evidence-based presentation on strategies used in residential care to support hydration of residents, and a review of the oral hydration typology ${ }^{16}$ ( $\left.\sim 35 \mathrm{~min}\right)$; (2) guided discussion (HK) on the impacts of COVID-19 procedures on hydration in residential care and potential solutions ( $25 \mathrm{~min})$; (3) assigned small breakout groups $(\mathrm{n}=4)$ to discuss oral hydration typologies (sipper, forgets to drink, fears incontinence, dysphagia and physically dependent) and potential strategies to support hydration for these residents ( $45 \mathrm{~min})$ and (4) large group debriefing on the small group discussions $(\sim 30 \mathrm{~min})$. A break was provided after the first large group segment. During the first large group session, participants were asked to reflect on what challenges had occurred with hydrating residents during the first wave of the pandemic and what strategies were used to overcome these challenges. In small group breakout discussions, 5-6 participants and 2-3 researchers were assigned to each virtual breakout room. Each of the four small groups was assigned two types of residents from the hydration typology ${ }^{16}$ (eg, sippers and persons with dysphagia). The lead for each small group (a member from the research team) asked two questions of participants for each typology: (1) what strategies would work best for residents who fit into this typology (eg, having 
dysphagia) and (2) how these strategies would need to be modified during an infectious outbreak. An effort was made by group leads to include all participants in the discussion, by using a 'round robin' approach for each question. 'Fearing incontinence' and 'dysphagia' were only discussed in one group each as they were expected to have fewer focused strategies, while 'sipper', 'physically dependent' and 'forgets to drink' were each discussed in two small groups. A second member of the research team took detailed fieldnotes. After the breakout sessions, the lead for each group shared comments on their discussion with the larger group and ideas were compared across groups. Zoom conference software provided the technology for this meeting; large group segments were audiorecorded, while small group discussion needed to rely on comprehensive fieldnotes. Zoom audiorecordings from the large group discussion and notes were stored on a secure server for analysis at the University of Waterloo.

\section{Analysis}

A postpositivist ${ }^{21}$ stance was taken to data collection and analysis, as the data were highly descriptive, based on participant observed practices and experiences, and resulted from the dynamics of the discussion and the values of participants. Immediately following the meeting, each dyad (facilitator and recorder) for the four small break out groups reviewed and filled in details on their individual notes and exchanged notes as a Word document to ensure completeness. These detailed notes were forwarded to the team leads (HK and CW) and CW amalgamated comments for specific hydration typology groups that were discussed in more than one small group (eg, sipper). CW and HK each reviewed the audiorecorded large group discussion where these small group session findings were reported back to determine any further details that were missed from the written facilitator and recorder notes.

CW and HK independently reviewed the first audiorecorded large group discussion focused on the effects of COVID-19 on resident hydration and strategies developed to promote hydration. Individual notes from this session completed by $\mathrm{HK}$ and $\mathrm{CW}$ were compared to determine any missing details. Word documents based on session notes underwent an initial content analysis ${ }^{22} 23$ and main concepts and draft tables/matrices were circulated among the larger research team prior to a virtual meeting. This virtual meeting of the research team was used to validate the findings extracted, as all members were present at the think tank; they also discussed how best to proceed with presentation of the data and what findings were most salient. Tables depicting key concepts were evolved and shared with the research team for confirmation prior to writing of textual results; further organisation of the tables to highlight findings was provided (eg, organise COVID-19 related challenges into resident, staff and home levels; strategies for hydration typology organised as supplies, home context). The large group sessions that were audiorecorded were reviewed again by
Table 1 Characteristics of participants $(n=27)$

\begin{tabular}{ll}
\hline Demographic characteristic & $\%$ Participants (n) \\
\hline Discipline & \\
\hline Nutrition & $44.4(12)$ \\
\hline Nursing & $18.5(5)$ \\
\hline Speech language pathologist & $11.1(3)$ \\
\hline Administration & $11.1(3)$ \\
\hline Food service & $7.4(2)$ \\
Other & $7.4(2)$ \\
Primary role & \\
Academic/researcher & $66.6(18)$ \\
\hline Provider & $33.3(9)$ \\
Country & \\
Canada & $77.8(21)$ \\
UK & $11.1(3)$ \\
USA & $7.4(2)$ \\
Germany & $3.7(1)$ \\
\hline
\end{tabular}

Participant characteristics. Table is original work and not previously published elsewhere.

CW for extraction of exemplary quotes. High level results were also shared with invited think tank participants if requested.

\section{Patient and public involvement}

No patients involved.

\section{RESULTS}

Meeting participants included 18 academics/researchers (10 from the research team) and 9 providers, with the majority from Canada $(78 \%)$; over half were from nutrition or food service disciplines. Participant details are provided in table 1. Participant comments on changes due to COVID-19 that impacted hydration were categorised as resident, staff or home related (table 2). Participants' suggestions for overcoming these challenges are also provided. Resident-related issues resulted from the confinement of residents to rooms during the first wave of the pandemic. Residents were interacting with staff only during care routines in their room and these touch points were minimised (at least initially) to prevent the potential spread of infection. This meant that access to beverages was limited as well as lack of social stimulation to drink. Isolated residents were reported to be bored and depressed, resulting in apathy and decreased appetite. One provider highlighted that as a result of the COVID-19 restrictions there were 'no volunteers, no exercise groups, no social activities... [this] would definitely make a downswing on the amount of liquid.' Solutions included using a trolley to delivery drinks between meals and providing socially distanced opportunities for residents to share fluids with others. 
Table 2 COVID-19 potential challenges to hydration and solutions offered

$\begin{array}{lll}\text { COVID-19 procedure } & \text { Hydration challenge } & \text { Potential solutions }\end{array}$

Resident Related

Residents confined to rooms

Restricted access to beverages; only

Offer trolley service of drinks between meals; beverages delivered by staff; lack of provide selection of preferred beverages including social stimulation to drink thickened fluids.

$\begin{array}{ll}\begin{array}{l}\text { Boredom/depression from room } \\ \text { isolation }\end{array} & \begin{array}{l}\text { Apathy, decreased appetite and lack of } \\ \text { interest in food and fluid consumption }\end{array} \\ & \begin{array}{l}\text { sharing fluids (eg, residents sitting near entrance } \\ \text { to rooms). } \\ \text { Provide popsicles and fun beverages. Put bells on } \\ \text { carts to announce drink trolley. }\end{array}\end{array}$

\section{Staff Related}

Limited entries by staff into residents' rooms and time spent with each resident; reduced medication passes
Decreased fluid offerings to residents

Lack of understanding of individual residents and how to support intake; residents may not respond to staff they do not recognise

$\begin{array}{ll}\text { Limited care staff } & \begin{array}{l}\text { Fluid intake reduced especially for } \\ \text { those who need support to eat }\end{array}\end{array}$

Shift in roles of staff
Food service staff no longer involved in Acronym checklist used by staff to ensure snack rotation to reduce opportunities for contamination; care staff do not know resident beverage preferences, increased burden on care staff

Professional staff working remotely Normal procedures for tracking and determining hydration are limited

Assume all residents at risk for dehydration and institute global processes to support hydration.

\section{Home Related}

Develop an 'all hands on deck' approach to providing beverages and meals. Shift mealtimes to make the meal longer.

encourage residents to drink.

Create new routines that include offering of fluid. Implement comfort rounds to check on all residents and offer fluid and other care needs.

Educate staff on how to approach residents and encourage intake.

resident needs are met (eg, SAFE: Social, Active, Fluid, Eating); use acronym at each contact with resident.

\section{Residents can't see staff face with PPE Tell the resident who they are (as face covered} drinking or special drinks brought by

Water coolers removed to reduce
contamination risk

Use of disposable glasses

Lack of freely available beverages: require staff to provide all beverages

Smaller volume, harder to hold and manipulate for residents (PPE)

Lack of family/volunteer visitors

Reduced opportunities for social family; reduced communication to staff around beverage preferences; cultural preferences not met

Convenience shop closed Beverage treats unavailable

Provide more fluids directly to residents at meals/ snacks.

Use preferred glassware, recognising that dishwasher will sufficiently sterilise. due to masks) or create unique aspects to uniform to promote identification by residents. Use verbal and nonverbal cues to prompt fluid intake; for example, mimic drinking.

Relocate support staff, such as recreation staff to provide hydration events and beverage passes to residents' rooms between meals. Encourage family to bring in items that could be quarantined for a few days and then provided to resident.

\section{Create hydration events (eg, Hawaiian luau} drinks). Use aportable convenience cart to provide special snacks and beverages for residents.

Physical distancing in dining rooms Residents spread out for beverage and Provide water automatically at meals for all meal delivery; more than one seating residents as well as preferred beverages. for meals required, resulting in reduced time for meals

Participant views on challenges and solutions to hydration during COVID-19 pandemic. Table is original work and not previously published elsewhere. 
Participants reported that COVID-19 precautions and procedures exacerbated longstanding issues of staff not prioritising hydration: 'If staff are already not thinking about hydration during normal operations, then they are certainly not thinking about hydration during pandemic times' (dietitian provider). Specific to COVID-19, limited staff, limited entries into residents' rooms and new staff resulted in decreased fluid offerings, lack of time to support drinking assistance and lack of understanding of residents' specific needs. Due to the many new tasks and activities required as infection control procedures, staff time was reported to be even more limited than usual for the routine tasks such as monitoring fluid intake. To promote hydration, participants suggested offering or encouraging fluid at every touch point. It was noted that systemic communication challenges among staff, such as lack of time to review documentation, impacted residentcentred practices, such as knowing individual drink preferences and how to support intake. New roles for staff were also a concern. In some homes, food service staff who usually provided between meal fluids through a snack service were removed from this activity, to minimise the number of staff entering a resident's room. Educating or communicating preferences and extending meals to allow for greater fluid consumption and including other staff at meals to meet eating assistance needs were key strategies offered. Finally, documentation on intake was deprioritised with the new required infection control procedures taking priority. One provider attendee described that the 'biggest challenge is sometimes [staff are] documenting everybody in the last fifteen minutes of their shift... we really question accuracy.' Considering that all residents are at risk for dehydration, it was deemed crucial to encourage the implementation of home-level efforts to promote hydration. For example, one participant reported that 'a lot of the processes and systems in long-term care [during the pandemic] is for residents to receive in-room service, rather than gather in dining rooms. Having that social aspect will encourage them to sit longer and have a few more sips, and improve their hydration.'

It was noted that, based on the suddenness of the COVID-19 pandemic in Canada, 'Decisions [are] made fast and the larger picture, which is [the] resident and their quality of life, is lost' (food service manager provider). There were several home-related effects due to pandemic procedures described by participants, but these varied across Canada and internationally, often because these decisions were left to the management of the home. For example, in some regions and homes, residents were not confined to their rooms, but grouped into smaller cohorts to increase physical distance during dining, while in others, residents were confined to their rooms and used disposable dishware and cups.

Several challenges were noted at the home level. High touch point areas such as self-serve beverages or water coolers were removed to reduce contamination. Similarly, a provider attendee noted that, with COVID-19, 'tuck shops are closed-they [residents] can't go out to get a drink like they used to.' The use of personal protective equipment resulted in challenges recognising and communicating with residents, while family/volunteer visits were abruptly stopped and physical distancing occurred in dining rooms. To overcome these challenges, staff were redeployed to provide support at meals, and recreation staff specifically launched hydration events using trolleys to deliver special drinks to residents' rooms. Strategies at the home level included education on the ability of industrial dishwashers to sufficiently sterilise dishware and on having staff wearing masks to introduce themselves to residents or have other identifying information readily visible for residents. Families were encouraged to bring in specialty items that could be quarantined.

The capacity to physically distance based on home configuration was reported to impact decisions about when and where food and beverages should be consumed. Offering water at every meal automatically provided an opportunity to support hydration. It was also noted that 'COVID-19 has rewound the clock with respect to factors that lead to malnutrition and dehydration' (dietitian provider). However, participants reported that crises such as the pandemic clarified for policy makers, homes, staff, residents and their families, what was important for residential care. They commented on the importance of working together with all staff being involved in promoting hydration and addressing challenges, the recognition that meals provide an important social opportunity for residents, and the understanding that families have a vital role in encouraging fluid intake and providing preferred beverages from outside the home. For instance, an attendee described that 'families have a beautiful way of getting their family members to eat and drink,' and another provider emphasised that 'families have been limited in bringing products into a facility or into a centre, and sometimes families are providing those special foods or treats that can't be accessed anywhere else, and that certainly is creating some issues in maintaining hydration overall.' The group felt that lessons could be learnt from the experience of COVID-19, and these should be incorporated into routines beyond the pandemic. For example, the rigid time frames for meals result in rushed care; during the pandemic, some homes extended the meal serving times out of necessity due to delivery of trays to resident rooms or having two seatings for meals to reduce numbers. This was seen as a positive practice that could be sustained postpandemic. Participants also noted that successful strategies targeted more than one challenge at time, for example: 'the key thing is that there has to be beverages available... so it's not adding too much work to their [staff members'] day, and it's part of their routine.'

The oral hydration typology ${ }^{16}$ was new to many participants, especially the providers. Ideas and strategies for supporting hydration using the typology for five resident subcategories of sippers, forgets to drink, fears incontinence, dysphagia and physically dependent are outlined 
in table 3 and categorised as: supplies, timing, facility context, socialisation and education. Examples for sippers include, identifying times when the resident drinks more as well as preferred beverages; offering beverages on a mobile cart at activities and promoting socialisation by having staff model drinking behaviours; or allowing residents to stay in the dining room to linger over their beverages. Making beverages accessible for those who forget to drink and providing between meal reminders and prompts, but also pairing these residents with tablemates who drink well were strategies provided by the group. Eating and drinking were noted to be social events and a key strategy offered was incorporating beverages into every communal activity in the home as '[residents] can't drink what is not offered' (nutrition researcher not from the research team). Educating staff on hydration needs and strategies to support these residents were other ideas. For those who fear incontinence, educating the resident on the importance of fluid intake and Kegel exercises while training staff (including non-nursing) to support them to the washroom when they are out of their personal room, were noted ways of helping these residents. For those with dysphagia, sufficient variety of thickened fluids, normalising a thickened texture to support hydration in all residents and educating the family and resident on the need for thickened fluids were ideas offered by participants for this group. For residents who are physically dependent on others, finding cups or using adaptive equipment that they could potentially use and drink from on their own were provided strategies. However, it was noted that sufficient trained staff or volunteers who can individualise support at meals, recreation activities and routine care (eg, brushing teeth, medication times) was needed.

Participants described that some form of assessment process would be needed to make the most of using the typology to identify strategies for individual residents. Trial and error were discussed as important for employing strategies at the individual level. A philosophy of care that promotes a social model was discussed as a means of promoting fluid intake across the typology subgroups. The continuous, mindful creation of new routines to offer beverages and assistance, as residents change in their capacity, was a key learning from the experience of the pandemic.

Understaffing was an overarching issue for addressing hydration that impacted all of the hydration typology. The pandemic has highlighted, especially for those who do not work in this sector, that residential homes are understaffed. Many of the strategies identified in tables 2 and 3 require staff for encouraging, creating opportunities, or aiding drinking. It is evident that hydration requires sufficient staffing and the concentration of all care tasks to the nursing staff during the first wave of COVID-19 likely exacerbated risk for dehydration. As one provider participant put it, 'in some sites, food service staff did have the responsibility of providing fluids, and with COVID-19, decisions had been made that there were risks associated with food service staff moving from one unit to another unit providing those fluids. That task was then removed for those individuals and put back to healthcare aides.' Education is a final overarching requirement to ensure adequate hydration, as reasons for not drinking vary. During the pandemic the continual replacement of staff, exacerbated by illness and policies of having only one home for employment, means that new and current staff need to be adequately and continuously trained.

\section{DISCUSSION}

There is insufficient research on improving resident fluid intake in residential care settings. ${ }^{7} 1524$ Considering the current context of the COVID-19 pandemic and framing the discussion using a typology of oral hydration, researchers and providers offered new insights on how the hydration needs of older adults in residential care can be met. Furthermore, new strategies were offered to expand on those originally reported with this typology. ${ }^{16}$ Consistent with the literature, ${ }^{611}$ our participants noted that hydration was rarely considered by residential providers and that consuming sufficient fluids requires time and effort on the part of the staff. This necessitates educating staff on the importance of hydration, the typology for low fluid intake, fluid needs and when challenges such as COVID-19 arise, not forgetting this basic need for residents. Providing fluid alone is not sufficient, as residents who can't drink need support from staff, and residents who won't drink need encouragement to do so. Consistent with our findings is the need to individualise strategies, ${ }^{11} 15$ which suggests that multi-component interventions should be trialled. ${ }^{611} 14$ However, there is a lack of consensus on how to tackle the complex causes of poor hydration in residential care. ${ }^{615} 24$ Most homes use selected individual strategies rather than consider the typology and multicomponent interventions. ${ }^{11}$ Further, standardised hydration education programmes are needed to support homes in raising awareness and motivating staff to emphasise fluid intake.

Evidence coincides with the strategies identified in this study including: considering the social and physical environments; providing prompts to drink; staff communication; access to fluids including beverage carts, cups and glasses; and, determining drink preferences. ${ }^{14}{ }^{24}$ Recent research suggests the value of mimicry to support fluid intake $\mathrm{e}^{25}$ and the use of technology to support communication of fluid intake among staff. ${ }^{26}$ A key outcome of this study is the consideration of individualised strategies to meet the specific needs of residents, rather than using global strategies and assuming they work for most. Prior research has noted that when interventions are tailored to the resident, such as considering their preferences and offering choice, there is an increase in fluid intake. ${ }^{27}$ Strategies outlined in table 3 mapped onto the oral hydration typology ${ }^{16}$ have the potential of ensuring that all residents' drinking needs are met. These strategies should be explored in further research.

COVID-19 has raised awareness of the challenges within residential care homes, and specifically the importance of sufficient, well-trained staff. ${ }^{19}$ As between-meal offerings can provide $70 \%$ of the fluid a resident consumes, ${ }^{28}$ 


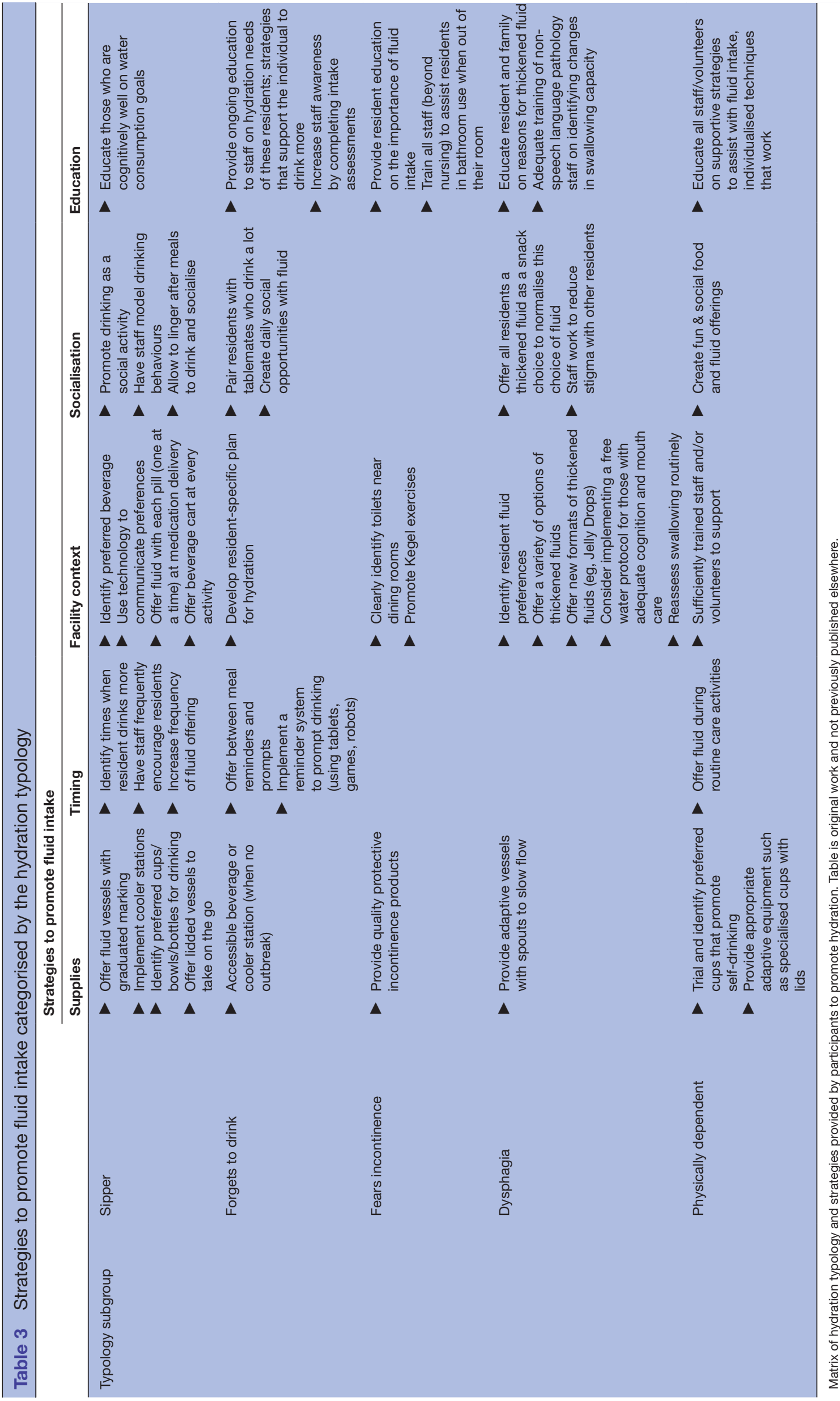


strategies must focus on such fluid offerings. During the pandemic, between-meal visits were noted by our participants to provide the resident with emotional and psychological support. Thus, there is a socialisation opportunity with frequently planned offerings of fluid between meals. As described by our participants, sufficient staffing and the need for improved communication of low fluid intake require special attention during an outbreak. Challenges due to the COVID-19 pandemic and potential novel strategies were offered at the resident, staff, and home levels. Finally, the added value of family and volunteers to support residents with essential tasks such as drinking were recognised when this care was suddenly withdrawn. ${ }^{19}$ Families are necessary to include in hydration interventions ${ }^{11}$ and several ideas were provided by our participants, such as sitting and drinking with residents or providing culturally preferred beverages. These ideas are worthy of exploration as part of the routine to promote hydration in residential care and for future research.

\section{Strengths and limitations}

Although this novel study investigates researcher and provider consideration of the oral hydration typology and examines how the pandemic has impacted the hydration of residents, this study has limitations. All providers were from Canada, and several invitees $(n=9)$ were unable to attend the meeting due to their workload and home priorities during the pandemic. This affects the generalisability of study findings. International experts, however, had direct experience with homes in their region and could speak to the challenges posed with COVID-19. Further, due to the platform used, we were unable to record the small group discussions; we included a facilitator and recorder in each group to capture this discussion, however this led to 10 of 27 participants being from the research team. Further, participants were invited from the networks of the research team; this potentially impacted the extent and generalisability of the strategies identified. The best practices for virtual focus groups are evolving and comfort with the virtual format and opportunity for discussion using this technology may have impacted findings. Audio files were not transcribed for large group discussions; however, two researchers individually reviewing the files and noting key concepts was considered sufficient for this descriptive qualitative content analysis. Finally, not all perspectives were garnered during this study. The views of family members and residents are missing, and this likely limited the problems identified and the potential solutions or strategies that could be employed to support hydration.

\section{CONCLUSIONS AND IMPLICATIONS}

This analysis provides a new perspective on hydration strategies mapped to an oral hydration typology ${ }^{16}$ and considers how these need to be modified during an infectious outbreak when residents are isolated to their rooms. Future research should create the evidence base for multicomponent interventions to address poor fluid intake of older adults living in residential care.

Author affiliations

${ }^{1}$ Schlegel-UW Research Institute for Aging, Waterloo, Ontario, Canada

${ }^{2}$ Department of Kinesiology and Health Sciences, University of Waterloo, Waterloo, Ontario, Canada

${ }^{3}$ Faculty of Nursing, University of Alberta, Edmonton, Alberta, Canada

${ }^{4}$ School of Dentistry, University of Alberta Faculty of Medicine and Dentistry,

Edmonton, Alberta, Canada

${ }^{5}$ Department of Food and Human Nutritional Sciences, University of Manitoba, Winnipeg, Manitoba, Canada

${ }^{6}$ School of Rehabilitation Science, McMaster University, Hamilton, Ontario, Canada

${ }^{7}$ School of Public Health Sciences, University of Waterloo, Waterloo, Ontario, Canada

${ }^{8}$ Independent Scholar, Sioux Falls, South Dakota, USA

${ }^{9}$ School of Nursing, University of California Los Angeles, Los Angeles, California, USA

Twitter Heather Keller @nutriagelab and Safura Syed @SafuraSyed

Contributors HK is the senior researcher for this project, leading on the methods, analysis and writing of the manuscript and is the guarantor. CW supported all aspects of the research including ethics submission, data collection and analysis and drafting of the manuscript. LM and SSI supported data collection, analysis and revision of the manuscript. JM, SSy, MNY, GH, PG, CL and ANM are original members of the research team and designed the study, were involved in data collection and analysis and revision of the manuscript.

Funding This work was supported by the University of Waterloo International Research Development Programme (no grant number), with matching funds from Adelphi University (start-up funds for ANM; no grant number), University of California at Los Angeles (no grant number), University of Manitoba University Grants Programme (\#51458) and University of Alberta School of Dentistry Oral Health Community Engagement Fund (CE2019-01).

Competing interests $\mathrm{HK}$ and GH are endowed research chairs. JM was the creator of the hydration typology used to frame this data collection.

Patient and public involvement Patients and/or the public were not involved in the design, or conduct, or reporting, or dissemination plans of this research.

Patient consent for publication Not applicable.

Ethics approval Ethics review and clearance was provided by the University of Waterloo Research Ethics Board (ORE \#41775). Participants gave informed consent to participate in the study before taking part.

Provenance and peer review Not commissioned; externally peer reviewed.

Data availability statement Data sharing not applicable as no datasets generated and/or analysed for this study. No data are available. No additional data available.

Open access This is an open access article distributed in accordance with the Creative Commons Attribution Non Commercial (CC BY-NC 4.0) license, which permits others to distribute, remix, adapt, build upon this work non-commercially, and license their derivative works on different terms, provided the original work is properly cited, appropriate credit is given, any changes made indicated, and the use is non-commercial. See: http://creativecommons.org/licenses/by-nc/4.0/.

ORCID iD

Heather Keller http://orcid.org/0000-0001-7782-8103

\section{REFERENCES}

1 Keller HH, Carrier N, Slaughter SE, et al. Prevalence and determinants of poor food intake of residents living in long-term care. J Am Med Dir Assoc 2017;18:941-7.

2 Lacey J, Corbett J, Forni L, et al. A multidisciplinary consensus on dehydration: definitions, diagnostic methods and clinical implications. Ann Med 2019;51:232-51.

3 Namasivayam-MacDonald AM, Slaughter SE, Morrison J, et al. Inadequate fluid intake in long term care residents: prevalence and determinants. Geriatr Nurs 2018;39:330-5.

4 Volkert D, Beck AM, Cederholm T, et al. ESPEN guideline on clinical nutrition and hydration in geriatrics. Clin Nutr 2019;38:10-47.

5 Institute of Medicine. Dietary Reference Intakes for Electrolytes and Water. In: Dietary reference intakes for water, potassium, sodium, 
chloride and sulfate. Washington DC: National Academies Press, 2005: 73-185.

6 Cook G, Hodgson P, Hope C, et al. Hydration practices in residential and nursing care homes for older people. J Clin Nurs 2019;28:1205-15.

7 Bunn DK, Hooper L. Signs and symptoms of Low-Intake dehydration do not work in older care home Residents-DRIE diagnostic accuracy study. J Am Med Dir Assoc 2019;20:963-70.

8 Keller H, Carrier N, Duizer L, et al. Making the most of mealtimes (M3): grounding mealtime interventions with a conceptual model. $J$ Am Med Dir Assoc 2014;15:158-61.

9 Donatelli NS, Somes J. Dehydration: when the recipe for care of the older adult does not include water. J Emerg Nurs 2018;44:84-5.

10 Masot O, Lavedán A, Nuin C, et al. Risk factors associated with dehydration in older people living in nursing homes: Scoping review. Int J Nurs Stud 2018;82:90-8.

11 Cook G, Hodgson P, Thompson J, et al. Hydration interventions for older people living in residential and nursing care homes: overview of the literature. Br Med Bull 2019;131:71-9.

12 Botigué T, Masot O, Miranda J, et al. Prevalence and risk factors associated with low fluid intake in institutionalized older residents. $J$ Am Med Dir Assoc 2019;20:317-22.

13 Mentes JC, Chang BL, Morris J. Keeping nursing home residents hydrated. West J Nurs Res 2006;28:392-406.

14 Bunn D, Jimoh F, Wilsher SH, et al. Increasing fluid intake and reducing dehydration risk in older people living in long-term care: a systematic review. J Am Med Dir Assoc 2015;16:101-13.

15 Wilson K, Dewing J. Strategies to prevent dehydration in older people with dementia: a literature review. Nurs Older People 2020;32:27-33.

16 Mentes JC. A typology of oral hydration problems exhibited by frail nursing home residents. J Gerontol Nurs 2006;32:13-19.

17 Canadian Institute for Health Information. Pandemic experience in the long-term care sector: how does Canada compare with other countries. Available: https://www.cihi.ca/sites/default/files/document/ covid-19-rapid-response-long-term-care-snapshot-en.pdf [Accessed June 2021]

18 Woo J. COVID 19 and residential care homes in Hong Kong. J Nurs Home Res Sci 2020;6:20-1.

19 Estabrooks CA, Straus S, Flood CM. Restoring trust: COVID-19 and the future of long-term care. Royal Society of Canada, 2020 Available: https://rsc-src.ca/sites/default/files/LTC\%20PB\%20\% 2B\%20ES_EN_0.pdf [Accessed June 2021].

20 Lewis F, Muzzy S. Conducting virtual focus groups, 2020. Available: https://www.mdrc.org/publication/conducting-virtual-focus-groups [Accessed June 2021].

21 Fox NJ. Post-positivism. In: Given LM, ed. The SAGE Encyclopaedia of qualitative research methods. London: Sage, 2008: 659-64.

22 Erlingsson C, Brysiewicz P. A hands-on guide to doing content analysis. Afr J Emerg Med 2017;7:93-9.

23 Hsieh H-F, Shannon SE. Three approaches to qualitative content analysis. Qual Health Res 2005;15:1277-88.

24 Oates LL, Price Cl. Clinical assessments and care interventions to promote oral hydration amongst older patients: a narrative systematic review. BMC Nurs 2017;16:4.

25 Nam S, Shune SE. Behavioral mimicry as a strategy to increase drinking behaviors in older adults. Am J Speech Lang Pathol 2020;29:1640-9.

26 Steven A, Wilson G, Young-Murphy L. The implementation of an innovative hydration monitoring APP in care home settings: a qualitative study. JMIR Mhealth Uhealth 2019;7:e9892.

27 Wilson J, Bak A, Tingle A, et al. Improving hydration of care home residents by increasing choice and opportunity to drink: a quality improvement study. Clin Nutr 2019;38:1820-7.

28 Jimoh OF, Brown TJ, Bunn D, et al. Beverage intake and drinking Patterns-Clues to support older people living in long-term care to drink well: DRIE and FISE studies. Nutrients 2019;11:447. 